\title{
Safety of the novel influenza viral vector Brucella abortus vaccine in pregnant heifers
}

\author{
Segurança de uma nova vacina vetorial empregando o vírus influenza \\ para Brucella abortus em novilhas prenhes
}

\author{
Kaissar Tabynov ${ }^{I^{*}}$ Sholpan Ryskeldinova $^{\mathrm{I}}$ \\ Zhailaubay Kydyrbayev ${ }^{I}$ Abylai Sansyzbay ${ }^{I}$
}

\section{ABSTRACT}

The present study provides the first information about the safety of a new influenza viral vector vaccine expressing the Brucella ribosomal protein L7/L12 or Omp16 containing the adjuvant Montanide Gel01 in pregnant heifers. Immunization of pregnant heifers was conducted via the conjunctival $(n=10)$ or subcutaneous $(n=10)$ route using cross prime and booster vaccination schedules at an interval of 28 days. The vector vaccine was evaluated in comparison with positive control groups vaccinated with B. abortus $S 19(n=10)$ or B. abortus RB51 $(n=10)$ and a negative (PBS+Montanide Gel01; $n=10)$ control group. Clinical studies, thermometry, assessment of local reactogenicity and observation of abortion showed that the vector vaccine via the conjunctival or subcutaneous route was completely safe for pregnant heifers compared to the commercial vaccines $\boldsymbol{B}$. abortus $S 19$ or B. abortus RB51. The only single adverse event was the formation of infiltration at the site of subcutaneous injection; this reaction was not observed for the conjunctival route.

Key words: Brucella abortus, vaccine, influenza viral vector, safety, pregnant heifer, thermometry, reactogenicity, abortion

\section{RESUMO}

O presente estudo fornece as primeiras informações sobre a segurança de uma nova vacina usando o vetor viral influenza para expressar as proteinas de Brucella L7/L12 ou Omp16, contendo o adjuvante Montanide Gel01 em novilhas prenhes. A imunização de novilhas prenhes foi realizada através das vias conjuntiva $(n=10)$ ou subcutânea $(n=10)$, empregadas na primovacinação e na dose de reforço. $O$ intervalo foi de 28 dias. A vacina empregando o vetor foi comparada com os grupos de controle positivo, vacinados com B. abortus $B 19(n=10)$ ou B. abortus RB51 ( $n=10)$ e um grupo de controle negativo (PBS + Montanide Gel01; $n=10)$. Os estudos clínicos, termometria, reação local e observação do aborto mostraram que a vacina empregando o vetor, aplicada pela via conjuntival ou subcutânea, foi completamente segura para novilhas prenhes, em comparação com as vacinas comerciais B. abortus B19 ou B. abortus RB51. $O$ único efeito adverso foi a formação de infiltrado no local da administração subcutânea; essa reação não foi observada no grupo vacinado pela via conjuntival.

Palavras-chave: Brucella abortus, vacina, vetor viral, segurança, novilha em gestação, termometria, reatogenicidade, aborto.

\section{INTRODUCTION}

Bovine brucellosis is caused by the Gram-negative bacterium Brucella abortus and can induce abortion and decrease fertility, and can also lead to chronic zoonotic infections in humans (GODFROID et al., 2005). At present, brucellosis among cattle is prevented using live attenuated vaccines B. abortus $\mathrm{S} 19$ (S19) or B. abortus RB51 (RB51). These vaccines offer high protectiveness, but have a number of serious disadvantages, primarily related to their ability to induce abortion in pregnant cows (SCHURIG et al., 2002). Furthermore, both strains are pathogenic to humans (ASHFORD et al., 2004). The shortcomings of existing commercial vaccines create difficulties in eliminating infection in brucellosis hotspots, particularly in countries with low economic level; therefore there is a high demand for new, effective, and safe vaccines against $\boldsymbol{B}$. abortus infection.

The objective of this research was to provide specific prophylaxis against $\boldsymbol{B}$. abortus, and

IThe Research Institute for Biological Safety Problems, Zhambulskaya oblast, Kordaiskiy rayon, 080409, Gvardeiskiy, Republic of Kazakhstan. E-mail: tabynov_81@mail.ru. "Corresponding author. 
we proposed and generated a novel vector vaccine based on the recombinant influenza A virus subtypes H5N1 or H1N1 expressing the Brucella ribosomal protein $\mathrm{L} 7 / \mathrm{L} 12$ or outer membrane protein-16 (Omp16). Our previous complex studies involving thermometry, clinical examination, hematology and blood biochemical analysis showed that the vector vaccine were completely safe for cattle compared to a commercial vaccine S19 (TABYNOV et al., 2014a). However, to completely confirm the safety of any kind of preventive preparation, especially brucellosis vaccines, is necessary to show that it does not induce abortion in vaccinated pregnant animals. On this basis, the purpose of the present study was to investigate the vaccine safety in pregnant heifers.

\section{MATERIAL AND METHODS}

\section{Bacterial strains}

The vaccine strains B. abortus S19 (Shchelkovsky Biokombinat, Moscow oblast, Russia) and B. abortus RB51 (Colorado Serum Company, Denver, CO, USA) were used in this study. Bacterial cells were cultured under aerobic conditions in Brucella Agar Base (Sigma-Aldrich, St. Louis, MO, USA) at $37^{\circ} \mathrm{C}$. All experiments with live Brucella were performed in the Research Institute for Biological Safety Problems and the biosafety level was 3 for the facilities.

\section{Generation of influenza viral vectors}

All influenza viral vectors (IVV) were generated by a standard reverse genetics method using eight bidirectional plasmids pHW2000. The detailed procedure for generation of IVV has been described previously (TABYNOV et al., 2014b; TABYNOV et al., 2014c). A total of four IVV subtypes expressing the Brucella L7/L12 or Omp16 proteins from the ORF of the $N S 1$ gene were generated: H5N1 (FluNS1-124-L7/L12-H5N1, Flu-NS1-124-Omp16H5N1) and H1N1 (Flu-NS1-124-L7/L12-H1N1 and Flu-NS1-124-Omp16-H1N1).

Vaccine preparation

Vaccines were prepared from the IVV Flu-NS1-124-L7/L12-H5N1, Flu-NS1-124-Omp16H5N1, Flu-NS1-124-L7/L12-H1N1 and Flu-NS1124-Omp16-H1N1; the vaccines were accumulated in 10-day-old embryonated chicken eggs (CE; Lohmann Tierzucht $\mathrm{GmbH}$, Cuxhaven, Germany) at $34^{\circ} \mathrm{C}$ for $48 \mathrm{~h}$. The titer of the IVV was determined in CE, as previously described (TABYNOV et al., 2012). The allantoic suspensions of IVV with the same antigenic structure $(\mathrm{H} 5 \mathrm{~N} 1$ or $\mathrm{H} 1 \mathrm{~N} 1)$ were combined in a single pool in a 1:1 ratio to obtain bivalent vaccine formulations, and then the mixtures of IVV (L7/ L12+Omp16) were mixed in a 1:1 ratio with sterile stabilizing medium containing $12 \%$ peptone from casein (Sigma-Aldrich) and 6\% saccharose (SigmaAldrich), mixed, aliquoted into $1 \mathrm{~mL}$ ampoules, lyophilized and stored at $2-8{ }^{\circ} \mathrm{C}$. Immediately before administration (via the conjunctival or subcutaneous route), the lyophilized vaccine was resuspended ( 1 or $2 \mathrm{~mL}$ per ampoule, depending on the route of administration) in a $20 \%$ solution of the adjuvant Montanide Gel01 (Seppic, Puteaux, France) in PBS.

\section{Animals}

A total of 50 pregnant (6-7 months pregnant; artificially inseminated) Kazakh white breed (meat direction) heifers aging 16-18 months-old were used in this study. All animals were seronegative for $\boldsymbol{B}$. abortus, which was confirmed by analysis of blood serum using the Rose Bengal test (RBT; Antigen, Almaty, Kazakhstan), serum agglutination test (SAT; Microgen, Moscow, Russia), complement fixation test (CFT; Microgen) and enzyme-linked immunosorbent assays (ELISA; Brucella-Ab C-ELISA, Svanova Biotech AB, Sweden) according to the manufacturers' instructions. Pregnancy was confirmed at an early stage (up to 60 days of pregnancy) using a hormonal method (progesterone concentration) and ultrasound and rectal palpation.

\section{Vaccination}

Pregnant heifers in the experimental groups were immunized twice via the conjunctival or subcutaneous route of administration at an interval of 28 days with vaccines generated from the IVV subtypes H5N1 (prime vaccination) and H1N1 (booster vaccination). The detailed animal immunization scheme is shown in table 1. Animals in the positive control groups (10 animals per group) were immunized once subcutaneously in the neck region (right side) with commercial vaccines S19 $\left(8.0 \times 10^{10} \mathrm{CFU}\right.$ animal $\left.^{-1}\right)$ or RB51 $\left(3.4 \times 10^{10} \mathrm{CFU}\right.$ animal $\left.^{-1}\right)$ according to the manufacturer's instructions. Pregnant heifers in the negative control group were subcutaneously administered with $2.0 \mathrm{~mL}$ of $20 \%$ Montanide Gel01 adjuvant in PBS. Each group of animals was kept in a separate room of a specialized facility for animal confinement and had free access to water and food throughout the experiment.

Assessment of vaccine safety

The safety of the vector vaccine via two different methods of administration (groups Flu-BA 
Table 1 - Schedule of immunization with the influenza viral vector $\boldsymbol{B}$. abortus vaccine for pregnant heifers.

\begin{tabular}{|c|c|c|c|c|}
\hline Group & Method of administration ${ }^{a}$ & Number of animals & $\begin{array}{l}\text { Dose prime vaccination (H5N1), } \log _{10} \\
\text { EID }_{50}(50 \text { percent Embryo Infectious } \\
\text { Dose) animal }{ }^{-1}\end{array}$ & $\begin{array}{lr}\text { Dose } & \text { booster } \\
\text { vaccination } & (\mathrm{H} 1 \mathrm{~N} 1), \\
\log _{10} \text { EID }_{50} \text { animal }^{-1}\end{array}$ \\
\hline Flu-BA $c$ & $\mathrm{c}$ & 10 & $7.7-8.0$ & $7.5-7.9$ \\
\hline Flu-BA $s c$ & s.c. & 10 & $7.7-8.0$ & $7.5-7.9$ \\
\hline
\end{tabular}

${ }^{a}$ The volume of vaccine for the conjunctival $(c)$ method of administration was $1.0 \mathrm{~mL}(0.5 \mathrm{~mL}$ to each eye) and $2 \mathrm{ml}$ for the subcutaneous ( $s c)$ method of administration.

c. or Flu-BA s.c.) was determined in comparison with the positive (B. abortus S19 or B. abortus RB51) and negative (PBS+Montanide Gel01) control groups. Clinical observation of the vaccinated animals was performed up to calving or abortion (for 3-4 months). Daily clinical thermometry observation of the vaccinated pregnant heifers was performed for 60 days post-initial vaccination (IV). Bacteriological examinations of aborted fetuses were performed as previously described (TABYNOV et al., 2014d).

\section{Statistical analysis}

The mean and standard error mean (SEM) of rectal temperature in groups of cattle were counted. The significance of the differences between groups was analyzed using two-way ANOVA followed by Dunnetts's multiple comparisons test. $P$ values $<0.05$ were considered significant.

\section{RESULTS}

Immunization of pregnant heifers with the vector vaccine via either the conjunctival or subcutaneous routes did not have any negative impact on the overall clinical status (behavior, appetite, etc.) of the animals or their course of pregnancy throughout the observation period. The rectal temperature of the animals in the experimental groups (Flu-BA c. and Flu-BA s.c.) remained within normal limits $\left(37.5-39.5^{\circ} \mathrm{C}\right)$ and had no statistically significant difference $(P>0.05)$ from the negative control group (PBS+Montanide Gel01) during the observation period (Figure 1). No side effects (expiration, conjunctivitis, etc.) were observed at the site of conjunctival administration; however, at the subcutaneous injection site, formation of infiltrates was noted in $100 \%$ of animals; these infiltrates formed within 7 days after vaccination were up to $5 \mathrm{~cm}$ in diameter and completely resorbed within 35 days after vaccination. It should be noted that a similar reactogenicity was observed in the animals of the negative control group.
In the positive control groups (S19 or RB51), no animals showed any signs of any disease or changes in behavior or appetite during the period of clinical observation, similarly to the animals in the negative control group. However, a significant $(\mathrm{P}<0.0001)$ increase in rectal temperature (up to $40.6^{\circ} \mathrm{C}$ ) was observed in animal groups vaccinated with S19 (at 1 and 2 days post-IV) or RB51 (on day 1 post-IV; Figure 1) compared to the negative control group. Moreover, in $40 \%$ of animals vaccinated with $\mathrm{S} 19$, formation of infiltrates up to $7 \mathrm{~cm}$ in diameter was noted at the injection site; the infiltrates completely resorbed within 14 days after vaccination. Additionally, in the animals vaccinated with S19, one calf aborted on day 56 after vaccination (approximately day 206 of pregnancy). Bacteriological and serological studies confirmed that abortion of this animal was caused by vaccination with S19 (smooth Brucella was isolated from the organs of the aborted fetus).

\section{DISCUSSION}

This paper is an important part of the authors' research and aimed to develop a new effective and safe vaccine against $\boldsymbol{B}$. abortus. Previous studies showed the IVV alone or in combination with the adjuvant Montanide Gel01 induced humoral and strong antigen-specific T-cell immune responses, and most importantly provided a high level of protectiveness comparable to that offered by a commercial S19 vaccine (TABYNOV et al., 2014c). We also showed that the vector vaccine in pregnant heifers provided good protection against $\boldsymbol{B}$. abortus 544 infection comparable to commercial vaccines B. abortus $\mathrm{S} 19$ or B. abortus RB51 (TABYNOV et al., 2014d). All previous studies of the vaccine safety were conducted exclusively in heifers, and therefore there is no information available in pregnant heifers. Previously, we recommend the conjunctival method as the route of administration for cattle; however, this method is associated with certain difficulties, 


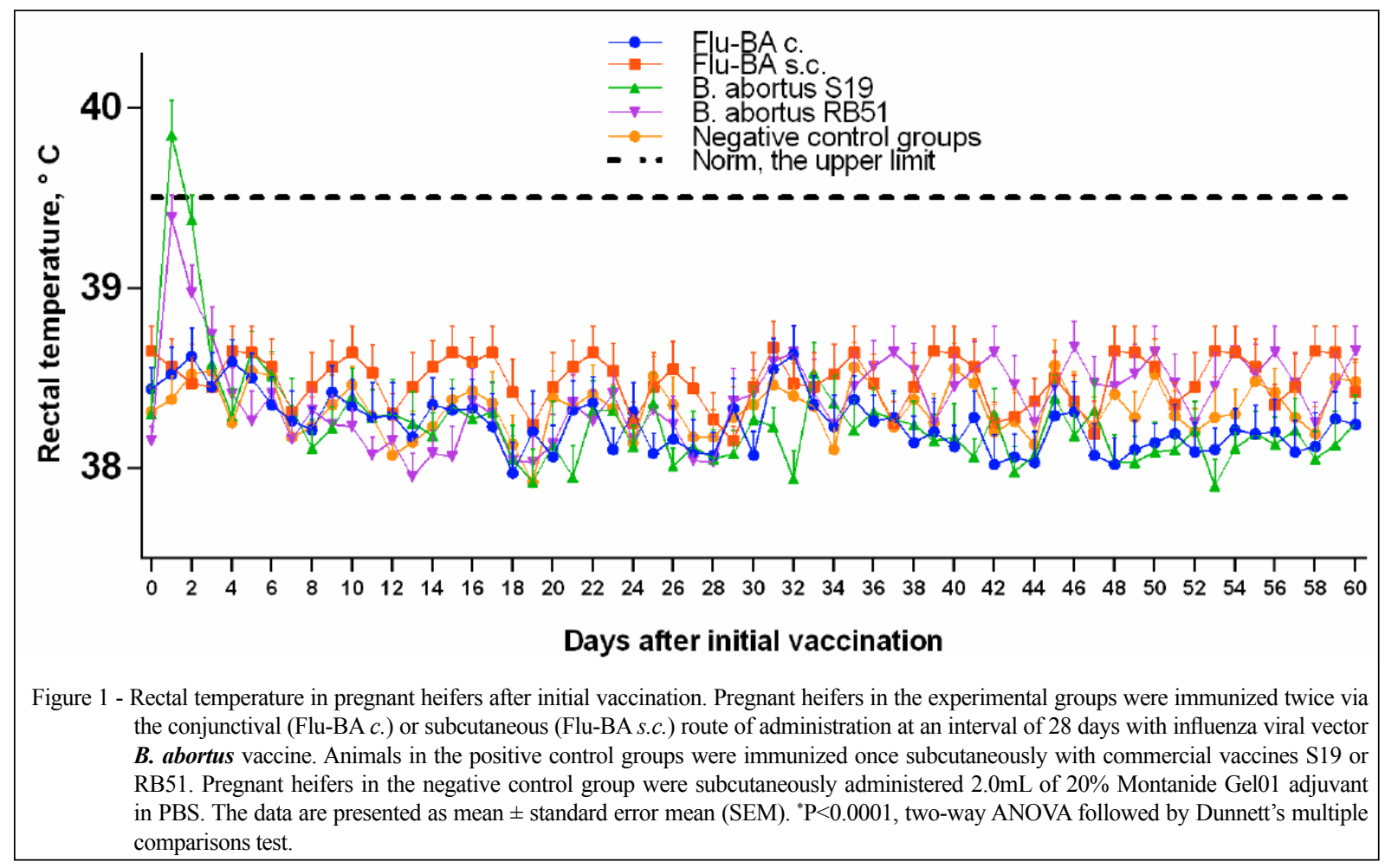

primarily a low productivity as it takes $5-10 \mathrm{~min}$ to vaccinate one animal and there is a complexity on controlling the dosage due to back flow of the vaccine out of the conjunctival sac. Therefore, in addition to the conjunctival method, we also tested subcutaneous immunization, a more convenient and widely-used method, in this study.

This research, which included thermometry and assessment of local reactogenicity and abortion, showed that the vector vaccine was completely safe for pregnant heifers via the conjunctival or subcutaneous methods of administration. Only one negative reactogenic side-effect was associated with the vector vaccine, i.e. the formation of infiltration at the site of subcutaneous injection of the vaccine; such a reaction was not observed in animals vaccinated via the conjunctival route. This local adverse reaction is likely to be primarily due to the adjuvant, as a similar reaction was observed in the negative control group vaccinated with PBS+Montanide Gel01. In our opinion, the reactogenicity of this vaccine preparation could be reduced by decreasing the concentration of adjuvant to $10 \%$, and also by reducing the volume used to resuspend the lyophilized vaccine (from $2 \mathrm{~mL}$ to $1 \mathrm{~mL}$ ). In contrast, serious adverse events were observed in the positive control group vaccinated with
S19, including both local (formation of infiltrates) and systemic reactions (increased body temperature), which were associated with abortion in one pregnant heifer. The adverse events observed in animals vaccinated with RB51 were minor and expressed exclusively as an increase in body temperature.

\section{CONCLUSION}

Thus, we can conclude that the new influenza viral vector vaccine against $\boldsymbol{B}$. abortus administered via the conjunctival or subcutaneous route in a prime and booster immunization mode is completely safe (with the exception of a mild reaction for the subcutaneous route of administration) for pregnant heifers. Although safe via the conjunctival route, after taking measures to reduce the reactogenicity of the vector vaccines (volume reduction and adjuvant concentration), we assume the use of a subcutaneous route may enable practical application of these vector vaccines.

\section{ACKNOWLEDGEMENTS}

We thanks to employees of the Research Institute for Biological Safety Problems, B. Yespembetov, N. Zinina, N. Assanzhanova, E. Kozhamkulov, D. Inkarbekov, T. Gotskina, I. Akzhunusova and N. Syrymkyzy for their technical assistance in

Ciência Rural, v.46, n.1, jan, 2016. 
studying the safety of the vector vaccine. This was work was carried out under the grant 1296/GF4 funded by the Science Committee of the Ministry of Education and Science of the Republic of Kazakhstan.

\section{BIOETHICS \\ AND COMMITTEE APPROVAL}

\section{BIOSECURITY}

This study was carried out in compliance with national and international laws and guidelines on animal handling. The protocol was approved by the Committee on the Ethics of Animal Experiments of the Research Institute for Biological Safety Problems of the Science Committee of the Ministry of Education and Science of the Republic of Kazakhstan (Permit Number: 0713/115).

\section{REFERENCES}

ASHFORD, D.A. et al. Adverse events in humans associated with accidental exposure to the livestock brucellosis vaccine RB51. Vaccine, v.22, p.3435-3439, 2004. Available from: <http://www. sciencedirect.com/science/article/pii/S0264410X04002154>. Accessed: sep 3, 2004. doi: 10.1016/j.vaccine.2004.02.041.

GODFROID, J. et al. From the discovery of the Malta fever's agent to the discovery of a marine mammal reservoir, brucellosis has continuously been a re-emerging zoonosis. Veterinary Research, v.36, p.313-326, 2005. Available from: <http://www.vetres.org/ articles/vetres/abs/2005/03/v4056/v4056.html>. Accessed: mayjun, 2005. doi: 10.1051/vetres:2005003.

SCHURIG, G.G. et al. Brucellosis vaccines: past, present and future. Veterinary Microbiology, v.90, p.479-496, 2002. Available from: <http://www.sciencedirect.com/science/article/ pii/S0378113502002559. Accessed: dec 20, 2002. doi: 10.1016/ S0378-1135(02)00255-9.
TABYNOV, K. et al. Safety of the novel vector vaccine against Brucella abortus based on recombinant influenza viruses expressing Brucella L7/L12 and OMP16 proteins, in cattle. Journal of Vaccines and Immunology, v.1, p.101, 2014a. Available from: $<$ http://www.peertechz.com/Vaccines-Immunology/JVI-1-101. php>. Accessed: apr 21, 2014.

TABYNOV, K. et al. Influenza viral vectors expressing the Brucella OMP16 or L7/L12 proteins as vaccines against B. abortus infection. Virology Journal, v.11, n.1, p.69, 2014b. Available from: <http://www.virologyj.com/content/11/1/69>. Accessed: apr 10, 2014. doi: 10.1186/1743-422X-11-69.

TABYNOV, K. et al. Novel influenza virus vectors expressing Brucella L7/L12 or Omp16 proteins in cattle induced a strong T-cell immune response, as well as high protectiveness against B. abortus infection. Vaccine, v.32, n.18, p.2034-2041, 2014c. Available from: <http://www.sciencedirect.com/science/article/ pii/S0264410X14002436>. Accessed: apr 11, 2014. doi: 10.1016/j. vaccine.2014.02.058.

TABYNOV, K. et al. Immunogenic and protective properties of the first Kazakhstan vaccine against pandemic influenza A (H1N1) pdm09 in ferrets. Virologica Sinica, v.27, n.6, p.345-352, 2012. Available from: $<$ http://link.springer.com/article/10.1007/ s12250-012-3272-7>. Accessed: nov 9, 2012. doi: 10.1007/ s12250-012-3272-7.

TABYNOV, K. et al. Novel vector vaccine against Brucella abortus based on influenza A viruses expressing Brucella L7/ L12 or Omp16 proteins: evaluation of protection in pregnant heifers. Vaccine, v.32, n.45, p.5889-5892, 2014d. Available from:<http://www.sciencedirect.com/science/article/pii/ S0264410X14012316>. Accessed: oct 14, 2014. doi: 10.1016/j. vaccine.2014.08.073. 